Recibido: 23/12/2021 --- Aceptado: 25/01/2022 --- Publicado: 09/02/2022

\title{
LA EVOLUCIÓN DE LA RELACIÓN ENTRE MARCAS E INFLUENCERS ESPAÑOLAS DE MODA TRAS LA PANDEMIA
}

\section{THE EVOLUTION OF RELATIONSHIP BETWEEN FASHION BRANDS AND SPANISH INFLUENCERS IN THE AFTERMATH OF THE PANDEMIC}

Daniel Guerrero-Navarro. Universidad de Málaga. España. dguerrero@uma.es

Carmen Cristófol-Rodríguez. Universidad de Málaga. España. carcrir@uma.es

Paloma Gutiérrez-Ortega. Universidad de Málaga. España. palomagutierrez.pg@gmail.com

\section{Cómo citar el artículo:}

Guerrero-Navarro, D., Cristófol-Rodríguez, C. y Gutiérrez-Ortega, P. (2022) La evolución de la relación entre marcas e influencers españolas de moda tras la pandemia. Revista de Comunicación de la SEECI, 55, 1-29. http://doi.org/10.15198/seeci.2022.55.e754

\section{RESUMEN}

La llegada del virus SARS-CoV-2 provocó una pandemia mundial y una crisis sanitaria que se extendió a todos los ámbitos de la sociedad, causando cierre de empresas, pérdidas de millones de empleos y numerosas alteraciones en el estilo de vida de los individuos, además de provocar cambios de consumo y un aumento del uso de las redes sociales debido al tiempo de confinamiento, lo que supuso un punto de inflexión en diversos ámbitos y, concretamente, en el sector de la moda y de las influencers. Al problema surgido por la pandemia, se suma el de la adaptación a la nueva regulación española del código de conducta en las redes sociales desde 2021 en España. Con la presente investigación se pretende analizar, mediante metodología mixta, los cambios producidos antes, durante y después de la pandemia en el trabajo de las influencers de moda, la evolución de las marcas de este sector en los medios digitales y las nuevas tendencias en el marketing de influencia que se han generado a raíz de esta nueva situación. Para ello, se ha realizado un análisis de contenido y una entrevista a profesionales del sector. Las conclusiones muestran superior control de los contenidos, aumento de seguidores y vínculo más estrecho con las marcas. Su comparativa con la dinámica existente en otros mercados internacionales, así como la adaptación en el futuro de la actividad profesional a las normativas vigentes, son las cuestiones más relevantes para poder ampliar el estudio en el futuro. 
Palabras clave: Influencia social; Marca; Moda; Redes Sociales; Publicidad; Patrocinio; Problema mundial.

\section{ABSTRACT}

In March 2020, the new SARS-CoV-2 virus arrived to stay amongst us, bringing the most important global pandemic known up to now. The entire world was affected by a health crisis that spread to all sectors of society, leading to company clousures, rises in unemployment rates and many changes in ordinary lifestyle. This pandemic has also had an impact on changes in society's consumption habits and a relevant increase in the use of social networks due to the months of lockdown, which has leaded to important changes in various areas and, specifically, in the fashion and influencers sector. In addition to the pandemic problem, there is the trouble of adapting to the new Spanish regulation, code of conduct on social networks, from January 2021. This research aims to analyze, using a mixed methodology, the changes produced in fashion influencers jobs before, during and after the pandemic, the evolution of fashion brands in digital media and new trends in influencer marketing that have been caused by this new situation. To do so, we have performed a content analysis and interviews with professionals from the fashion sector. Conclusions show a greater control of content, an increase in number of followers and a closer link with brands. Comparisons with the dynamic in other international markets, as well as the future adaptation of the professional activity to current regulations, are the most relevant questions to be addressed in order to be able to expand the study in the future.

Keywords: Social Influence; Fashion; Social Networks; Brand; Advertising; Sponsoring; World problems.

\section{A EVOLUÇÃO DO RELACIONAMENTO ENTRE MARCAS DE MODA ESPANHOLAS E INFLUENCIADORES APÓS A PANDEMIA}

\section{RESUMO}

A chegada do vírus SARS-CoV- 2 provocou uma pandemia global e uma crise sanitária que se alastrou a todas as áreas da sociedade, causando o fechamento de empresas, a perda de milhões de empregos e inúmeras alterações no estilo de vida dos indivíduos, além de provocar alterações no consumo e um aumento da utilização das redes sociais devido ao tempo de confinamento, que foi um ponto de viragem em vários aspectos e, especificamente, no setor da moda e dos influenciadores. Soma-se ao problema decorrente da pandemia a adaptação ao novo regulamento espanhol do código de conduta nas redes sociais a partir de 2021 na Espanha.Esta pesquisa tem como objetivo analisar, por meio de uma metodologia mista, as mudanças produzidas antes, durante e após a pandemia no trabalho dos influenciadores da moda, a evolução das marcas desse setor nos meios digitais e as novas tendências no mundo, geradas como resultado desta nova situação. Para isso, foi realizada uma análise de conteúdo e uma entrevista com profissionais do setor. As conclusões mostram um controle superior dos conteúdos, aumento de seguidores e uma ligação mais próxima com as marcas. A sua comparação com a dinâmica existente em 
outros mercados internacionais, bem como a futura adaptação da atividade profissional às normas vigentes, são as questões mais relevantes para poder alargar o estudo no futuro.

Palavras chave: Influência social; Marca; Moda; Redes sociais; Publicidade; Patrocínio; Problema mundial.

\section{INTRODUCCIÓN}

En los últimos años, se ha producido una transformación social ligada a la digitalización, que se ha visto reflejada también en la comunicación. Castells (2009) advertía de la influencia en individuos y sociedades de la acuñada "revolución digital" en diversos aspectos vitales, como en las relaciones entre seres humanos, las cuales "están presentando cambios importantes en diferentes rutinas y contextos cotidianos, esto es, en las formas de: establecer contacto, crear relaciones de amistad, planear viajes, realizar autovalidación y manejar procesos de aprendizaje, entre otros" (Barón et al., 2021).

En esta línea, es evidente que "el carácter sinérgico de las nuevas tecnologías marca los procesos productivos y comunicacionales de nuestra era a nivel mundial" (Jódar, 2010), otorgando a organizaciones e individuos un amplio abanico de oportunidades comunicacionales.

En esta nueva era digital, los medios han virado hacia la digitalización, que los ha llevado hasta el momento actual, en el que los portales online se diversifican, existiendo numerosos canales a través de los cuales acceder a información especializada. Además, los medios convencionales se han unido al mundo online a través de espacios propios y mediante la presencia en plataformas de discusión, las cuales les permiten conversar con sus públicos en un proceso de comunicación bidireccional que crea una relación y un vínculo. Estas plataformas son las denominadas redes sociales.

Las redes sociales corresponden al término que empezó a emplearse por antropólogos y sociólogos ingleses a mediados de los años 50 del siglo XX, para caracterizar y estudiar el conjunto de relaciones humanas que tienen un impacto duradero en la vida de un individuo y ofrecen unos patrones y colaboraciones contingentes para orquestar las soluciones en la vida cotidiana (Wolfe, 2011).

Es evidente la influencia de las redes sociales y su uso en los individuos. Según cifras del portal Statista (2021), existen más de 3.600 millones de personas en el mundo que utilizan las redes sociales actualmente. En España, según el Estudio Anual de Redes Sociales 2021, 25,9 millones de españoles de entre 16 y 65 años las utilizan. Todos ellos encuentran en estas un medio a través del cual comunicarse, establecer relaciones con personas afines a ellos y compartir pensamientos, intereses, parte de sus vidas, respuestas a preguntas o expectativas e, incluso, trabajo (Arenas, 2010).

Una vez que los medios de comunicación y las marcas han tomado conciencia de las oportunidades que les ofrecen las redes sociales, se crea "un nuevo modelo económico, productivo y social que supone la aparición de industrias, perfiles 
profesionales y modelos económicos" (Jódar, 2010) desconocidos hasta ese momento. Asimismo, los modelos publicitarios evolucionan con respecto a los clásicos, tomando gran protagonismo el denominado branded content o contenido de marca, "inspirados en las teorías de la narrativa transmediática" (Ruiz, 2017).

Siguiendo los datos ofrecidos por el Estudio INFOADEX (2021) de la Inversión Publicitaria en España de este último año, se comprueba que el branded content sigue en auge, ya que se posiciona en quinto lugar del ranking por su volumen sobre la inversión total.

\subsection{Instagram como divulgador de contenidos de moda y belleza}

La aplicación Instagram, creada en 2010, tenía como finalidad principal compartir imágenes y vídeos. En 2012, fue adquirida por Facebook, alcanzando los 700 millones de usuarios mensuales activos en 2017 (Guerrero, 2017). Desde entonces, la aplicación ha experimentado multitud de cambios que han ido adaptándose a las necesidades y deseos de los usuarios. Según advertía Rose en 2017, y tal y como confirman los datos ofrecidos por el Estudio Anual de Redes Sociales 2021 en España realizado por IAB, "Instagram es una de las redes sociales más importantes en el panorama digital actual". Además, actualmente se sitúa junto a Whatsapp como las redes sociales utilizadas con mayor frecuencia entre los usuarios. Su público se sitúa principalmente entre los 16 y los 45 años, siendo mayoritariamente femenino (65\%).

Siguiendo con los datos obtenidos por dicho estudio, advierte que, de manera global, un $97 \%$ de los usuarios las emplean para seguir perfiles de sus familiares y entorno más cercano, seguido de un $56 \%$ que afirma seguir a influencers, y un $52 \%$ que siguen a perfiles de marcas. Este porcentaje ha disminuido con respecto a los resultados obtenidos el año 2019.

Sin embargo, un $59 \%$ de los usuarios investiga a través de las redes sociales antes de realizar la compra de algunos productos, situándose Instagram como la tercera red social preferida para ello, siendo la elegida por el $36 \%$ de los usuarios, porcentaje que continúa creciendo con respecto a años anteriores.

Según Mention Solutions (2021), el 83\% de las personas registradas en Instagram había descubierto nuevos productos o servicios a través de esta plataforma y el $80 \%$ han decidido comprar algún producto o contratar algún servicio tras consultar con la información de este soporte (Casaló et al., 2018)

Todo ello hace de Instagram una red social apta para el entretenimiento y la interacción, que favorece el consumo y el contacto con las marcas y la difusión de estas y de sus productos entre usuarios a través del "boca a boca" (Khan, 2018). A ello se suma la existencia de diversas estrategias de comunicación mediante las cuales se facilita la búsqueda de información específica, como el contenido difundido por influencers de un sector concreto, un perfil atractivo con contenido útil para el usuario que ayude también a comercializar los productos y servicios a través de una buena imagen acorde con la marca (Rose, 2017) y a fidelizar a los seguidores y clientes. 
A través de ella, los usuarios han creado una red que incluye a marcas, influencers, insiders, medios de comunicación, agencias y clientes que se relacionan entre ellos creando un escaparate perfecto para el momento social en que vivimos. Las marcas de moda tienen el reto de trasladar su universo al medio online (Velar et al., 2019), e Instagram les facilita acercarlo a sus públicos. Para Cristófol et al. (2018) "cualquier empresa o marca puede hacer uso de la publicidad en Instagram" pero son los influencers en moda los que mejor acogida han tenido.

Entre los nuevos canales, consideramos que Instagram es el que mejor responde a estas nuevas necesidades. Como afirma Alonso (2020), se trata de la red visual más potente que existe y una herramienta de comunicación perfecta para la industria de la moda. (...) Su tasa se incrementa por encima de las de Twitter y Facebook (Velar et al., 2020; L2 Fashion Team, 2017; Silva, 2014). Por tanto, estos datos confirman que Instagram es una vía eficaz para difundir, promocionar y vender productos, marcas y servicios

\subsection{Influencers: definición, tipos y función en el mundo de la moda y la belleza}

Hoy en día, los usuarios cuentan con la capacidad de poder conectar con las marcas en el momento que deseen, rompiendo así con el modelo unidireccional de los medios de comunicación tradicionales. En este sentido, Costa (2015, p.8) afirma que:

(...) toda marca tiene un sustrato real y se inserta en su contexto social, económico, cultural y tecnológico concreto. Toda marca está enraizada en la realidad de la gente y de sus vidas cotidianas, de sus citas, sus aspiraciones y sus sueños. La marca se visualiza y se sintetiza en un símbolo que se posiciona en la memoria de cada quien.

Siguiendo estas palabras, las marcas buscan incentivar esos puntos de conexión con sus clientes, asegurándose, además, de ofrecer información y contenidos útiles para el público al que se dirige. En este contexto y gracias a internet, surge la figura de lo que hoy en día conocemos como influencers.

Como sostiene de Castro, (2019), los influencers "son individuos con una marca propia, a menudo conocida como marca personal o self branding, que desarrollan una imagen pública distintiva para obtener ganancias comerciales y/o capital cultural". Si bien la figura de los líderes de opinión se remonta al inicio de las civilizaciones, las influencers conocidas tal y como entendemos hoy su figura, tienen origen en las blogueras que publicaban, de manera amateur, sus conocimientos y vivencias a través de la web Blogger.com.

En el caso del mundo de la moda, el primer blog dedicado al sector nace en 2003, bajo el nombre "No good for $m e^{\text {", }}$ editado por una joven americana que posteaba acerca de su estilo y sus propias reflexiones acerca de diversos temas. Con el paso del tiempo, la "blogosfera" experimentó una expansión masiva, cifrándose el número de blogs en julio de 2010 en más de 3 millones (Luque, 2019). 
Una vez se realizó este salto de soportes, "gracias al impacto del que gozan en redes sociales, sus seguidores conectan con ellos de tal forma que no sólo los ven como una forma de entretenimiento, sino que siguen su estilo de vida, y valoran sus experiencias y opiniones" (de Castro, 2019). Sin embargo, este nuevo empleo, que surge como una necesidad de unir de manera inmediata a los clientes con las marcas, no es una técnica novedosa.

Esta terminología clásica se encuentra ligada a lo que anteriormente conocíamos como "líder de opinión", término que surge a raíz de los medios de comunicación de masas. En este sentido, como sostienen Lazarsfeld et al. (1944) y Katz (1955), en su teoría de la comunicación "two-step flow of communication", muchas de las ideas llegan a las masas a través de los líderes de opinión, gracias a la influencia personal que ciertas personalidades tenían en función de sus comportamientos y actitudes y no solo a través de los medios de comunicación.

En relación con esto, según Regadera (2020), es evidente que los consumidores buscan personas o empresas en las que confiar. Esto ha llevado a que también las marcas deban reforzar los vínculos con los influencers. Es por ello por lo que surge la necesidad de proporcionar una respuesta rápida y una imagen que consiga fidelizar al cliente, surgiendo así "la comunicación bidireccional asentada sobre las bases de un diálogo y una relación de identificación y confianza entre marcas, influencers y seguidores, que se muestra más necesaria que nunca" Alonso (2020).

La figura del influencer cuenta con habilidades comunicativas que hacen que, mediante su contenido, sean capaces de crear tendencias y corrientes de influencia (Merodio, 2013).

Los influencers de las nuevas plataformas on line, en especial de Instagram, actúan no solo como intermediarios de las marcas o embajadores de las mismas, sino que también se convierten en un medio publicitario con capacidad de segmentación, feedback, credibilidad e influencia entre su público de seguidores, que son características que favorecen el éxito de su actividad. (Cardoso, 2018).

Además, a la hora de tener en cuenta los tres rasgos que definen a un influencer, Díaz (2017) los agrupa en: familiaridad, capacidad de comunicación y experiencia.

Sin embargo, esta figura no sigue un único patrón, llegando así a existir una clasificación según la tipología de estos. Siguiendo con Díaz (2017) y la clasificación de influencers de Barón (2015) en su Pirámide del Influencer Engagement, y pese a emplear términos diferentes, ambos defienden tres tipos de influencers.

Celebrities: personalidades que dan el salto de offline al mundo online (Díaz, 2017). Se les reconoce de manera fácil, ya que aparecen constantemente en televisión, prensa y anuncios. En este caso, los consumidores perciben a estos prescriptores como publicidad y, de esta manera, como un nuevo camino que se les presenta a las marcas para llegar a ellos. Suele responder a objetivos que están relacionados con el marketing tradicional y no con el marketing de influencia, en este caso nos referimos a una mejora en la imagen de marca y en un aumento de notoriedad (Barón, 2015). 
Líderes de opinión: blogueros, periodistas y personas expertas en un tema en concreto. Comparten contenido especializado con su comunidad de fans. Podrían incluirse aquí a aquellos individuos no famosos, pero que se han dado a conocer en redes sociales y crean su comunidad y sus contenidos. Además, este tipo de influencers cuenta con la fidelidad de sus seguidores, siendo superior a la de los celebrities (Díaz, 2017).

Micro-Influencers. consumidores actuales que muestran cierta actividad en las redes y están comprometidos con una marca en concreto. Baron (2015) afirma que, a pesar de que la comunidad de este grupo cuenta con un tamaño menor que el del resto de tipologías de influyentes, el poder de repercusión en sus seguidores y la relación con estos es mayor. "Su comunidad se caracteriza por ser muy participativa" Díaz (2017).

El objetivo de este grupo es potenciar las decisiones de compra, principalmente por la cercanía y la confianza que este tipo influyente recibe de sus seguidores.

\subsection{Covid en el sector de la moda y la belleza}

En los últimos meses en los que la COVID-19 ha afectado al sector de moda y belleza, Instagram ha permitido que centenares de empresas subsistan a través de estrategias comunicacionales desarrolladas en la plataforma.

Según la agencia de marketing Comunicare (2021), "en 2019, antes del golpe de la COVID-19, el tamaño mundial de la industria de la moda se situaba en 1.409 .618 millones de dólares, de manera que, en dos años la moda habrá perdido un $9 \%$ de su volumen". Además, "las ventas de prendas de moda y complementos se desplomaron un $39,8 \%$ en 2020 por el impacto que ha tenido la crisis sanitaria del coronavirus en el sector" (Comunicare, 2021).

Por esta razón, este sector se ha visto en la necesidad de reinventarse, rediseñarse y buscar otras alternativas de negocios. Es en este sentido donde aparece el comercio online, alternativa que, según valora Salesupply (2021), "representaron el 15,4\% del sector de la moda en España, frente al 8,8\% en 2019".

Además, con la llegada y consecuencias de la pandemia, ha existido un aumento en el consumo de redes e internet en los usuarios: "el engagement rate promedio de los influencers fue 43 veces más alto por publicación de influencers que por anunciantes en los meses de abril y mayo" (Chiorboli, 2020). Esta alternativa ha resultado prácticamente la única opción que mantenían las marcas para poder mostrar, presentar o publicitar sus productos y servicios a sus públicos durante los meses de confinamiento. Según Comscore (2020), "durante el primer mes del confinamiento, el consumo de redes aumentó un 55\%".

La pandemia ha reforzado la digitalización y la ha convertido en un aliado, favoreciendo el crecimiento de las diversas herramientas digitales con las que la sociedad cuenta hoy en día y aumentando la red tecnológica de usuarios como futuros consumidores potenciales para diferentes negocios. 
Para San-Cornelio (2020), investigar sobre comunicación en redes sociales en pandemia tiene cinco premisas esenciales: tiempos rápidos, investigación lenta; lo que ocurre en una red, no ocurre en otra; la importancia de las imágenes; probablemente, el mayor reto sea el metodológico; las cuestiones éticas.

\subsection{Comunicación de moda en redes sociales}

Ya desde el comienzo de la publicidad como profesión, numerosos expertos en comunicación han investigado para determinar los mejores canales para que las marcas y anunciantes logren impactar de manera eficiente a sus públicos objetivos. Usuarios y consumidores están cada vez más informados, debido al continuo uso de internet y al papel tan importante que esta desempeña en la vida de cualquier ciudadano. En esta línea, la gran cantidad de contenidos a los que las personas se enfrentan cada día crea inseguridad acerca de la veracidad de la información que se proporciona (Coleman, 2012; Laato et al., 2020).

Actualmente, a través de la comunicación digital, los jóvenes consiguen obtener información novedosa de la industria textil gracias a las redes sociales y a los influencers. Asimismo, diferentes acciones de comunicación en moda como pueden ser promocionar una marca, servicio, producto o incluso campañas y distintos eventos pueden verse reforzados e impulsados favorablemente gracias a la repercusión del influyente, siendo este la estrategia, ya que también se trata de un líder de opinión y ya cuenta con un público que va a prestar su atención, dándole así mayor fuerza, respaldo y fortaleza a la campaña publicitaria" (Peréz et al., 2020).

\section{OBJETIVOS}

La presente investigación pretende concluir cuáles han sido los principales cambios que ha experimentado el trabajo y el contenido de las influencers especializadas en el sector de la moda y la belleza. Para ello, se apoya en diversas técnicas cualitativas que permiten conocer cuáles son las nuevas tendencias que han llegado para quedarse en la comunicación con influencers del sector, cuáles han desaparecido y cómo es el nuevo método de trabajo a seguir entre las prescriptoras, las marcas y los usuarios. En relación con esto se establecen dos objetivos fundamentales, que son los siguientes:

1. Conocer la evolución experimentada en el trabajo de las influencers para marcas y empresas del sector de la moda durante y tras la pandemia.

2. Identificar las nuevas tendencias y acciones presentes en el trabajo de las influencers de moda.

Para hallar una respuesta objetiva y concluyente que permita cumplir con los objetivos anteriormente mencionados, partimos de diversas hipótesis:

1. Las influencers especializadas en moda y belleza han modificado su forma de trabajo debido a la pandemia.

2. Se han visto obligadas a modificar el tipo de contenido que comparten en sus perfiles de Instagram a causa de la pandemia.

3. Su relación con las marcas de moda y belleza se ha visto afectada o modificada a 
partir de la pandemia y a causa de esta.

4. No han cumplido con la nueva normativa de autocontrol y código de conducta durante los meses de pandemia.

Se pretende analizar cómo ha evolucionado el trabajo de las influencers en el sector de moda y belleza a raíz de la llegada de la pandemia. Además, se busca determinar cuáles son las nuevas tendencias en el marketing de influencers de moda y belleza fruto de la adaptación. Para ello, se emplearán técnicas de investigación mixtas, es decir, técnicas de carácter cualitativo, como la entrevista en profundidad con profesionales del sector; y de carácter cuantitativo, como el análisis de contenido.

Para este último caso, se estudiarán diferentes publicaciones realizadas en periodos de tiempos determinados y se tendrán en cuenta las variables determinadas por el número de seguidores actual de cada influencer, la cantidad de likes y comentarios, los tipos de publicación, las marcas que aparecen en los posts y cómo son introducidas en el contenido realizado, la localización de la imagen o vídeo, y cómo aparece la influencer en esta (con mascarilla, sola, acompañada, etc.).

\section{METODOLOGÍA}

Esta investigación, de carácter exploratorio, es pertinente ya que aporta una visión analítica del panorama actual en el marketing con influencers del sector de moda y belleza. Entre la incertidumbre actual es conveniente conocer cómo se encuentra el mercado y hacia qué caminos se enfoca, además de exponer cómo influencers y marcas se han adaptado.

Además, el caso de estudio atañe a una situación que permanece en el tiempo, que aún no ha concluido, por lo que, no solo aporta información sobre un hecho poco estudiado, si no que deja la opción abierta para próximas investigaciones que sigan analizando cómo evoluciona el sector de las influencers de moda y belleza en las diversas etapas de la pandemia.

Para cumplir con los objetivos planteados, es conveniente aplicar técnicas de investigación que permitan obtener datos con los que confirmar o refutar las hipótesis propuestas, pues como afirman López y Sandoval (2016), "la metodología de la investigación se definía como la descripción, explicación y justificación de los distintos métodos utilizados en la conducción de la investigación".

Para ello, esta investigación se basa en métodos cuantitativos y cualitativos que, como sostienen dichos autores, "ambos tipos de metodologías de investigación consisten en un conjunto de técnicas para recoger datos, donde los métodos cualitativos han sido tan refinados y estandarizados como otros enfoques investigativos" (López y Sandoval, 2016). Para Figuereo et al. (2021) los estudios sobre influencers en Instagram "presentan gran variedad de aproximaciones metodológicas para responder a sus objetivos de investigación, pasando por diseños cuantitativos, mixtos y cualitativos".

En primer lugar, se hará uso de una técnica cualitativa, ya que, según Lee y Lings, "la metodología cualitativa no solo sirve para explorar y describir, sino que también 
facilita el desarrollo del trabajo investigativo hacia la obtención de explicaciones significativas ante un fenómeno" (Ugalde y Balbastre, 2013). Piza et al. (2019) afirman que "la metodología de la investigación cualitativa tiene gran relevancia en la investigación científica aunque sus métodos y técnicas son usados con mayor frecuencia en las ciencias del comportamiento social y humano".

En este caso, la principal técnica cualitativa que se aplicará será la entrevista en profundidad a profesionales del sector del marketing con influencers de moda y belleza.

Para Blasco y Otero (2008) "La entrevista es una de las técnicas cualitativas más utilizadas, que sirve para construir el sentido social de la conducta individual o del grupo de referencia al que pertenece el individuo entrevistado, a partir de un conjunto de saberes privados". Según Baquedano (2021), "la entrevista en profundidad es una técnica de investigación cualitativa que busca comprender las opiniones, perspectivas, experiencias y motivaciones de las personas entrevistadas, en relación a los temas que hemos definido en nuestro estudio". Además, con el análisis cualitativo se recurre a guiones con preguntas poco estructuradas para que el entrevistado tenga plena libertad para responder y no se coarte con preguntas cerradas. Gracias a esto, se fomenta la participación y el debate sin que exista ningún tipo de condicionante (León, 2020; Taylor \& Bogdan, 2008).

Por ello, y atendiendo a las necesidades de la investigación, se llevará a cabo como técnica cuantitativa el análisis de contenido, comprendido por Krippendorff (1990) como una técnica de investigación destinada a formular inferencias reproducibles y válidas a partir de ciertos datos codificados. Es un conjunto de procedimientos interpretativos de mensajes, textos o discursos, basado en técnicas de medida cuantitativas o cualitativas, que tienen como objetivo elaborar y procesar datos relevantes sobre las condiciones de producción o empleo posterior de dichos mensajes, textos o discursos (Piñuel, 2002).

En este caso, se empleará uno de los modelos de análisis planteados por Krippendorff y plasmados por Colle (2011): el diseño de la estimación, que permite acceder a un fenómeno y "observar estimaciones de ciertos parámetros o verificar determinadas hipótesis".

A pesar de ello para Lozares Colina (2005) afirma que

el análisis de redes sociales se inscriben en una gran constelación de teorías cuya denominación o marco general se intuye pero de la que queda mucho por encontrar y bautizar, sobre todo para las ciencias sociales (...). Sencillamente forman otra galaxia aún poco explorada por los sociólogos en general por los científicos sociales. (Lozares, 2005).

De esta manera, se analizará cómo ha evolucionado el trabajo de las influencers a partir de la pandemia y se plantearán nuevas tendencias de contenido que se hayan dado a partir de esta situación. 
Para poder llevar a cabo una recogida de datos eficaz, se han elegido dos muestras representativas no probabilísticas que permitan conocer la realidad del sector del marketing con influencers de moda y belleza.

Así, en el caso de la entrevista, partiendo de la población conformada por todas las influencers, y tras comprobar la accesibilidad de las principales influyentes, según el número de seguidores, y teniendo en cuenta los perfiles más destacados del sector a través de la repercusión en medios de comunicación especializados y otros perfiles en la red social Instagram, se han elegido los perfiles de tres influencers del panorama español situadas en diferentes rangos en cuanto a número de seguidores se refiere, con distinto carácter estilístico y digital, que las acercan a distintos tipos de públicos siendo, igualmente, profesionales más o menos relevantes en el mundo de la moda online. De esta manera, la muestra final quedaría descrita en la siguiente tabla:

Tabla 1.

Perfil de las influencers entrevistadas.

\begin{tabular}{|c|c|c|c|}
\hline Nombre & Perfil Instagram & $\begin{array}{c}\text { Num. Seguidores } \\
\text { (diciembre 2021) }\end{array}$ & Marcas con las que colabora \\
\hline $\begin{array}{c}\text { Beatriz Prados } \\
\text { Fernández }\end{array}$ & @beapfernandez & $44,2 \mathrm{~K}$ & $\begin{array}{c}\text { Antik Batik, Loewe, Sèzane, Ron Brugal, } \\
\text { Pull and Bear, Batiste, etc. }\end{array}$ \\
\hline $\begin{array}{c}\text { María Calvet } \\
\text { Anguela }\end{array}$ & @maria.calvet & $54,1 \mathrm{~K}$ & $\begin{array}{c}\text { Duas Swimwear (propia), Brownie, Nakd, } \\
\text { Studio Fantastique,Angel Schlesser, Estee } \\
\text { Lauder, etc. }\end{array}$ \\
\hline $\begin{array}{c}\text { Patricia Sañes } \\
\text { Iborra }\end{array}$ & @patriciasanes_ & $166 \mathrm{~K}$ & $\begin{array}{c}\text { Jesús Peiró, Grupo Lamadrid, Louis Vuitton, } \\
\text { Agua Bendita, Castañer, Andrés Sardá, } \\
\text { Anthropology, Nespresso, etc. }\end{array}$ \\
\hline
\end{tabular}

Fuente: Elaboración propia

Por otro lado, para llevar a cabo el análisis de contenido, se ha optado por una unidad de análisis conformada por seis macro-influencers, cuyos contenidos y trayectorias son bastante relevantes en España. La muestra vuelve a ser de carácter representativo y no probabilístico, puesto que ha sido escogida a conciencia bajo los parámetros anteriormente mencionados. Las influencers cuyo perfil ha sido analizado son:

Tabla 2.

Perfil de las influencers analizadas.

\begin{tabular}{|l|l|l|l|}
\hline Nombre & $\begin{array}{l}\text { Perfil } \\
\text { Instagram }\end{array}$ & $\begin{array}{l}\text { Núm.Seguidores IG } \\
\text { (dic'21) }\end{array}$ & Marcas con las que colabora \\
\hline $\begin{array}{l}\text { Alexandra } \\
\text { Pereira }\end{array}$ & $\begin{array}{l}\text { @alexandra } \\
\text { pereira }\end{array}$ & $2,145 \mathrm{MM}$ & $\begin{array}{l}\text { Lovely Pepa (propia), Cartier, Yves Saint } \\
\text { Laurent, APM Monaco, Chanel, Dolce \& } \\
\text { Gabbana, etc. }\end{array}$ \\
\hline $\begin{array}{l}\text { Aida } \\
\text { Domenech } \\
\text { (Dulceida) }\end{array}$ & @dulceida & $2,969 \mathrm{MM}$ & $\begin{array}{l}\text { Dulceida Shop (propia), Dior, Coca Cola o } \\
\text { Versace, Calzados Krack, Sephora, etc. }\end{array}$ \\
\hline Sara Baceiredo & @sarabace & $432 \mathrm{~K}$ & It's Lava (propia), Loewe, Clinique, Pull and \\
\hline
\end{tabular}


Guerrero-Navarro, D., Cristófol-Rodríguez, C. y Gutiérrez-Ortega, P.

La evolución de la relación entre marcas e influencers españolas de moda tras la pandemia

\begin{tabular}{|l|l|l|l|}
\hline & & Bear, Laagam, Marieth, etc. \\
\hline Lucía Bárcena & @luciabarcena & $397 \mathrm{~K}$ & $\begin{array}{l}\text { Petra Swimmwear (propia), Barey (socia), } \\
\text { Polin et Moi, Brownie, Michonet, Antik Batik, } \\
\text { Louis Vuitton, Isdin, Claudie Pierlot, etc. }\end{array}$ \\
\hline $\begin{array}{l}\text { María Fdez. } \\
\text { Rubíes }\end{array}$ & @mariafrubies & $740 \mathrm{~K}$ & $\begin{array}{l}\text { Intimissimi, Pertegaz, Bulgari, Esteé Lauder, } \\
\text { etc. }\end{array}$ \\
\hline Mery Turiel & @meryturiel & $889 \mathrm{~K}$ & $\begin{array}{l}\text { Mute Wine (propia), Calzedonia, Kiko Milano, } \\
\text { Mango, Inditex, Rosa Pedroche, Ze García, } \\
\text { etc. }\end{array}$ \\
\hline
\end{tabular}

Fuente: Elaboración propia

Una vez determinadas las técnicas de investigación y elegidas las muestras para cada una de ellas, se procede a realizar la recogida de datos entre los días 22 y 27 de julio, para poder extraer resultados y conclusiones favorables a la investigación.

En primer lugar, para la extracción de datos del análisis de contenido, se ha establecido un periodo de tiempo que abarca la primera y última semana de los meses de enero y febrero de 2020, dando cobertura a la actividad del ejercicio de las prescriptoras antes de la pandemia; la primera y última semana de los meses de abril y mayo del mismo año, con la finalidad de reflejar la adaptación del trabajo de las influencers durante los meses de confinamiento; y, por último, la primera y última semana de los meses de enero y febrero de 2021, para poder tener una visión de cómo es la realidad del marketing de influencers de moda y belleza en el periodo actual de pandemia y poder compararlo con el tiempo anterior a esta.

Para reflejar los datos y la información obtenida en el análisis, se ha elaborado una tabla por cada etapa temporal, que permite agrupar la información obtenida. En ella queda reflejada la cantidad de seguidores actuales de cada influencer, el número de likes y comentarios que ha obtenido cada publicación en este periodo, signo inequívoco y definitorio del engagement generado por cada una; el formato de cada publicación, el tipo de contenido que muestra en ella: si aparecen o no marcas en la publicación, si se trata de trabajos publicitarios o publicaciones de carácter personal; si aparece señalizada la actividad publicitaria que realizan o no mediante los hashtags: \#ad, \#supplied, en colaboración con, etc.; si el contenido está realizado en un medio exterior 0 interior; si aparecen con mascarillas 0 sin ellas (especialmente en las publicaciones realizadas durante el confinamiento y tras él) y si aparecen en solitario o, por el contrario, acompañadas.

Una vez se han introducido en las tablas todos los datos, se traducirán de manera cuantitativa en gráficas donde puedan contemplarse de manera clara y resumida los resultados del análisis con respecto a cada uno de los factores analizados.

Por último, para obtener resultados esclarecedores acerca de la relación entre las influencers y las marcas, se ha llevado a cabo el envío de algunas preguntas que abordan ciertas cuestiones relacionadas con ello y con la evolución del trabajo de las 
influencers durante y después de la pandemia a las influencers mencionadas en páginas anteriores a través de correo electrónico.

\section{RESULTADOS}

\subsection{Resultados del análisis de contenido}

Tras analizar el contenido publicado por las influencers que conforman la muestra elegida para la investigación, se han obtenido diferentes resultados según los factores estudiados.

El primer factor en la investigación ha sido el número de seguidores de cada influencer. Si bien es un dato interesante y destacable para poder comprender el resto de los resultados de esta investigación, cabe destacar que es el número actual de cada uno de los perfiles.

En primer lugar, se ha analizado la cantidad de publicaciones totales realizadas por las integrantes de la muestra durante el periodo de estudio, y se han analizado los likes y comentarios que han obtenido en cada una de sus publicaciones para poder considerar cuál ha sido la evolución del engagement de cada una.

\section{Figura 1.}

Total de publicaciones.

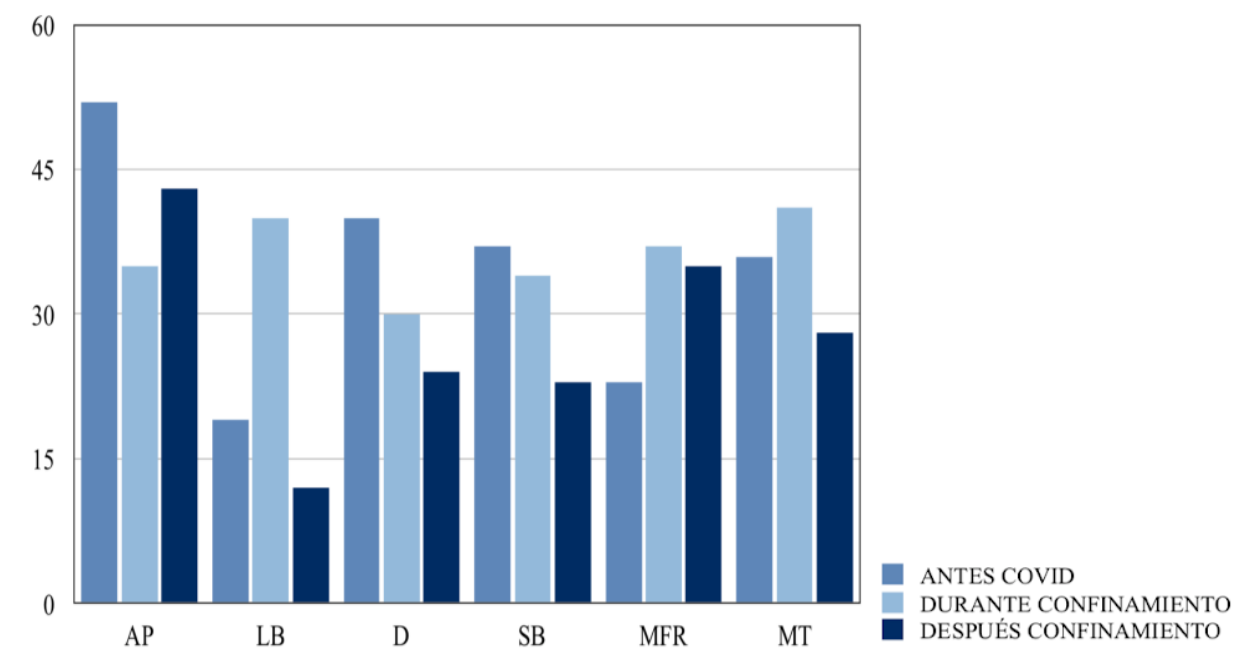

Fuente: Elaboración propia

Considerando el número de publicaciones totales realizadas en los periodos de estudio, se puede apreciar cómo las influencers con mayor número de publicaciones antes del COVID coinciden con los perfiles más internacionales, en este caso Alexandra Pereira y Dulceida. Su contenido está producido en un alto porcentaje en el extranjero, en diferentes viajes de trabajo y ocio.

Ambas son las que experimentan una mayor reducción de publicaciones durante los meses de confinamiento, mientras que el resto de influencers, a excepción de Sara Baceiredo, quien también registra una disminución en su producción, aumenta la cantidad de contenido publicado, destacando los bruscos cambios en datos de Lucía 
Bárcena, que pasa de 19 publicaciones en el primer periodo de estudio, correspondiente a enero y febrero de 2020, a 40 publicaciones en las semanas de análisis que suceden durante el confinamiento y se reduce esta cantidad a 12 posts publicados en los días analizados entre enero y febrero de 2021.

Seguidamente, se procede al estudio y análisis de la cantidad de likes y comentarios obtenidos en las publicaciones de cada perfil.

Figura 2.

Media de likes por publicación.

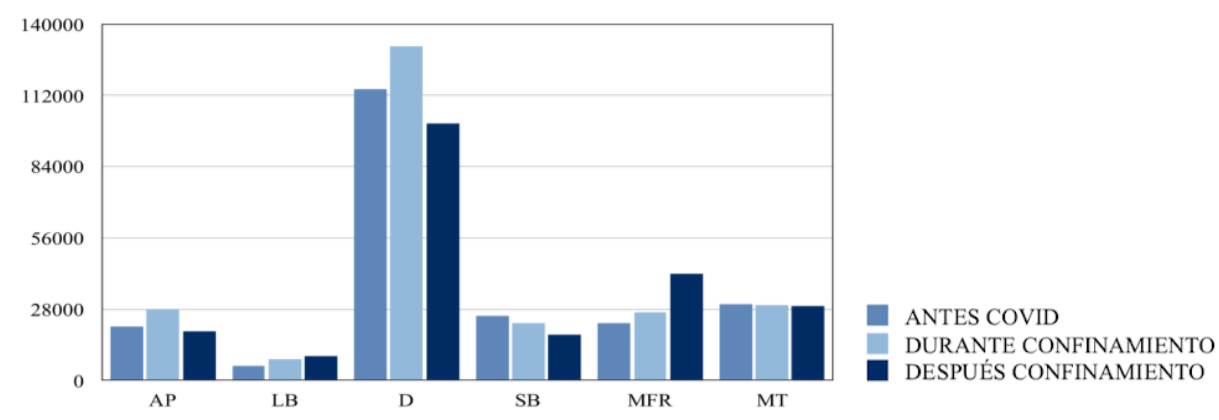

Fuente: Elaboración propia

Es destacable la cantidad de likes que obtiene Dulceida, siendo comparada con el resto de sus compañeras, pues consigue una media de 114.630 likes en el periodo anterior a la llegada de la pandemia, dato que aumenta hasta los 131.406 durante los meses de confinamiento. Por otro lado, cabe resaltar cómo la influencer internacional Alexandra Pereira obtiene una media menor en número de likes que sus compañeras, teniendo una diferencia de más de 1 millón de seguidores entre ellas.

Mientras Alexandra obtiene 21.094 likes de media antes del confinamiento, 28.053 durante el mismo y 19.198 en los meses posteriores, Sara Baceiredo acumula una media de 22.404 durante enero y febrero de 2020, Mery Turiel 29.657 en los meses de cuarentena y María Fernández-Rubíes 41.927 en enero y febrero del año 2021; dato también destacable y que puede estar estrechamente relacionado con el nacimiento de su primer hijo, un hecho que obtuvo bastante repercusión en redes sociales. En reglas generales, se aprecia cómo el número de likes disminuye tras el confinamiento.

Para continuar la observación y análisis del engagement, se ha tenido en cuenta también el estudio de la media de comentarios por publicación. 


\section{Figura 3.}

Media de comentarios por publicación.

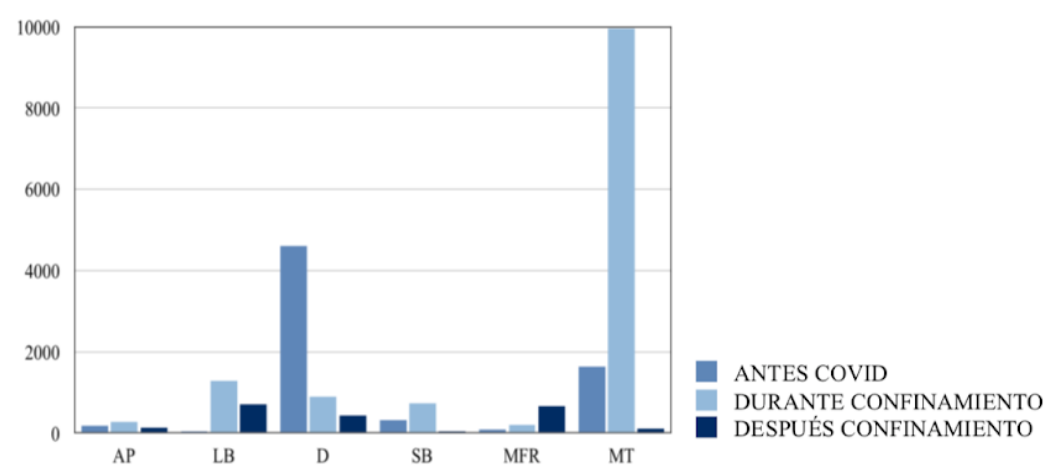

Fuente: Elaboración propia

En este caso se aprecia cómo las cifras generales son bajas en comparación con los likes. Aun así cabe resaltar diferentes valores: en primer lugar, la media de comentarios de Mery Turiel durante los meses de confinamiento, equivalente a 9.952 comentarios; la cifra de Dulceida en los meses pre-pandemia, con 4.608 comentarios de media, o la cantidad que acumula Lucía Bárcena en este mismo periodo de tiempo.

Todas estas cifras tienen un fenómeno en común: la celebración de sorteos en alguna publicación del perfil. Esto hace que la media de comentarios aumente considerablemente. Llama también la atención el receso de comentarios que obtiene Sara Baceiredo en sus publicaciones en los meses de enero y febrero de 2021, situándose su media en 35 comentarios, cuando la cifra del periodo de estudio anterior ascendía a 733 comentarios de media.

En general, se observa la disminución de engagement tras los meses de confinamiento, pese a haber experimentado en tónicas generales un aumento durante el periodo de cuarentena. Destaca el reducido engagement que acumula Alexandra Pereira, pese a ser la segunda influencer con mayor número de seguidores; la fidelidad de la comunidad de Mery Turiel, bastante constantes en cifras generales; y los altos valores de Dulceida, generadora del mayor engagement entre las influencers de moda en España.

Volviendo al número de publicaciones publicadas por cada influencer, se ha analizado la cantidad de estas en las que el contenido estaba elaborado en un exterior o, por el contrario, desde el interior de algún lugar, con la finalidad de apreciar otro de los cambios considerables que han debido experimentar las generadoras de contenido en estos meses de pandemia. 


\section{Figura 4.}

Total publicaciones en interior.

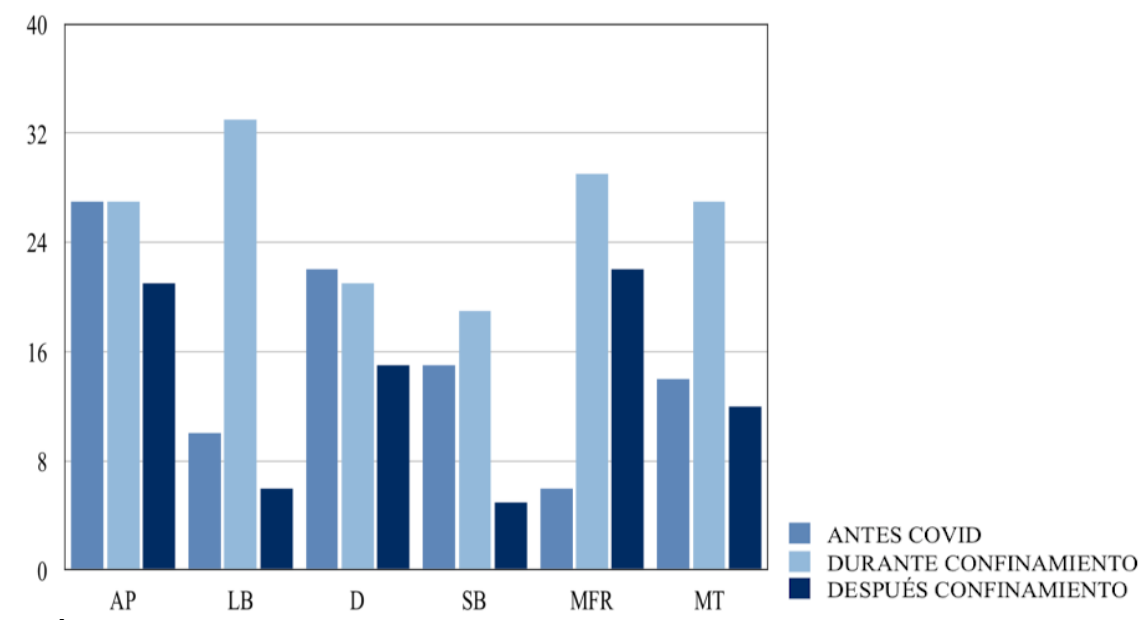

Fuente: Elaboración propia

En lo que respecta al contenido generado en espacios interiores, se aprecia un considerable crecimiento durante los meses de confinamiento, siendo el más brusco el caso de María Fernández-Rubíes, quien, acostumbrada a mostrar a sus seguidores sus looks desde las calles de Madrid, pasó de 6 publicaciones en interior en el periodo de estudio anterior a la llegada de la COVID-19, a 29.

En el caso de Dulceida, pese a descender la cantidad de publicaciones en interior, hay que tener en cuenta otros factores, como la publicación de contenidos realizados en meses anteriores a la pandemia y posteados durante las semanas de confinamiento o las publicaciones realizadas en el interior de espacios públicos o pertenecientes a cadenas de restaurantes, hoteles, empresas, comercios, etc. que realizaba en el periodo de enero y febrero de 2020.

Por otro lado, el aumento de publicaciones en interior que experimenta el perfil de Lucía Bárcena corresponde también a un aumento del número de publicaciones en estas semanas, cuyo contenido es generado de manera diaria. Finalmente, es destacable la brusca reducción en la cantidad de contenido en interior que las influencers realizan una vez pasado el periodo de confinamiento, siendo en todos los casos menor la cantidad de posts realizados en interior en el periodo comprendido entre enero y febrero de 2021, especialmente entre las influencers más jóvenes de la muestra: Sara Baceiredo y Lucía Bárcena. 


\section{Figura 5.}

Total publicaciones en exterior.

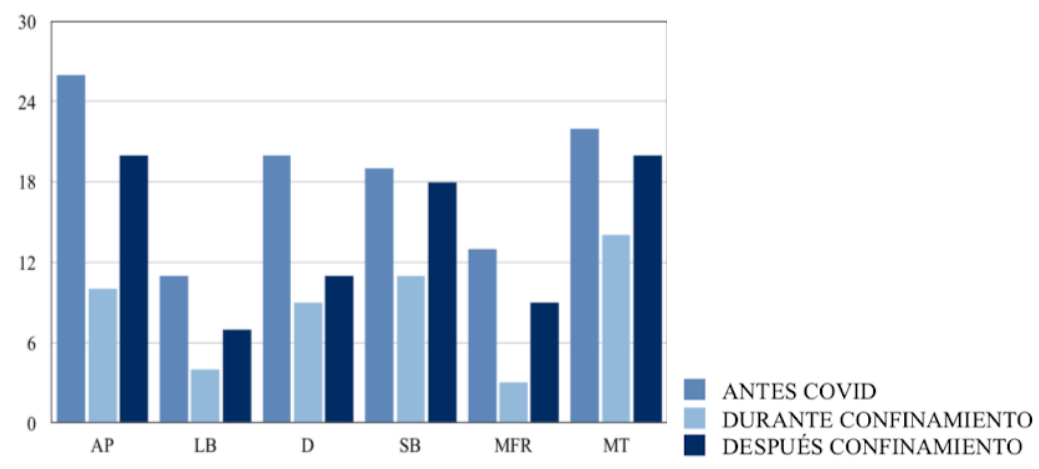

Fuente: Elaboración propia

Por el contrario, se puede apreciar cómo la cantidad de publicaciones en el exterior se reducen considerablemente en todos los casos durante el periodo de estudio correspondiente a las semanas de confinamiento, mientras que, tras él, vuelven a aumentar de manera exponencial, siendo el caso más destacable el de Alexandra Pereira.

A continuación, se pasa a analizar la evolución que ha experimentado la aparición de marcas en las publicaciones de las influencers seleccionadas, con o sin marca.

\section{Figura 6.}

Total publicaciones sin marca

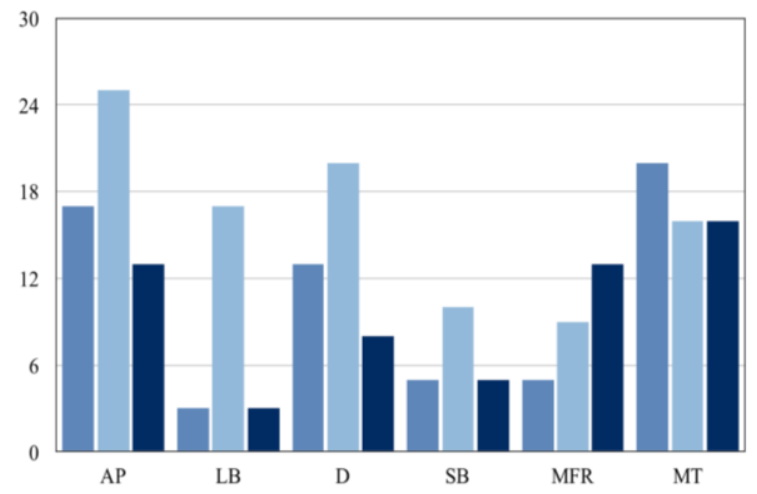

Fuente: Elaboración propia

En este análisis se aprecia el incremento de publicaciones sin mención alguna a marcas durante los meses de confinamiento, y es que, en este periodo, el contenido publicado generalmente es de carácter más personal o realizado con anterioridad, por lo que en el momento de publicarlo no tienen el compromiso con la marca, lo que les exime de mencionarla.

Todo ello tuvo como finalidad en un principio mantener la audiencia, sin embargo, probablemente, tras experimentar la buena acogida que obtuvieron en datos con este tipo de publicaciones, han mantenido en menor medida una línea más personal en algunos de los posts tras la etapa de confinamiento, como queda reflejado en la 
gráfica superior, fiel reflejo del análisis de contenido llevado a cabo.

En este caso, son Alexandra Pereira, Lucía Bárcena y Dulceida las influencers cuyo contenido más se alejó de las marcas en estas semanas, siendo las mismas, junto a Sara Baceiredo, las que menor cantidad de este tipo de contenido han mantenido en los meses de enero y febrero de 2021.

En cambio, cabe recordar que, desde el 1 de enero de 2021, entró en vigor el Código de Conducta sobre el Uso de Influencers en la Publicidad, (Autocontrol, 2020) realizado por la Asociación Española de Anunciantes y Autocontrol junto con los Ministerios de Asuntos Económicos y Transformación Digital y de Consumo, con el objetivo de controlar que las menciones publicitarias de los influencers puedan ser reconocibles e identificadas como publicidad, eliminando así la publicidad encubierta.

Por ello, otros de los factores estudiados han sido las publicaciones en las que las influencers advertían del carácter publicitario de la publicación, y, por el contrario, aquellas publicaciones en las que aparecían marcas de manera explícita a través de menciones, productos o etiquetado, pero en las que no se referenciaba si pertenecían a un encargo publicitario de la marca.

Figura 7.

Total publicaciones con marca.

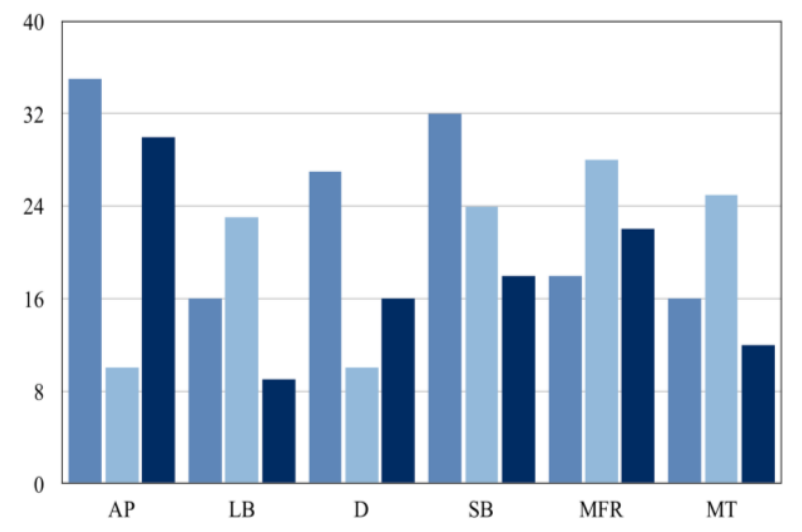

ANTES COVID

DURANTE CONFINAMIENTO

DESPUÉS CONFINAMIENTO

Fuente: Elaboración propia

En este caso, se puede apreciar cómo las influencers que trabajan principalmente con marcas de lujo e internacionales, como Alexandra Pereira y Dulceida, son las que reducen en mayor medida las publicaciones en las que éstas aparecen, lo que puede ser un síntoma más de que, durante los meses de confinamiento, las marcas de lujo decidieron parar y reducir su actividad publicitaria, mientras que las marcas de menor envergadura apostaron por la publicidad con influencers para seguir teniendo una visibilidad necesaria para sus negocios.

La disminución de marcas en las publicaciones realizadas en el periodo postconfinamiento, correspondiente en esta ocasión a los meses de enero y febrero de 2021, puede estar influida por la entrada en vigor de la Ley de autocontrol en la 
publicidad con influencers, pues, como se observa en el caso de Sara Baceiredo o Lucía Bárcena, es habitual el etiquetado de las marcas de prendas y productos que aparecen en el contenido que publican pese a no ser contenido publicitario, simplemente por responder de manera global al interés de los usuarios que las siguen y por aportar visibilidad a su perfil a través de la aparición en el feed de las marcas.

Este hecho cambia con la nueva Ley, pues al ser obligatorio el etiquetado de la publicidad, se ven en la obligación de justificar aquellas apariciones en las que realizan colaboración o acciones publicitarias para las marcas, lo que las lleva a evitar el etiquetado a no ser que sea, verdaderamente, una colaboración publicitaria.

En el caso de María Fernández-Rubíes, el aumento de publicaciones con marcas, se ve claramente influido por el reportaje con la revista Hola! de su nueva casa, donde muestra las estancias y el mobiliario de la misma.

Dentro de todas las publicaciones con marcas que se han encontrado en el análisis de contenido, se han dividido en dos tipos de publicaciones diferentes: aquellas en las que la publicidad está claramente señalizada y aquellas en las que no se determina si es o no publicidad.

\section{Figura 8.}

Total publicaciones publicitarias señalizadas.

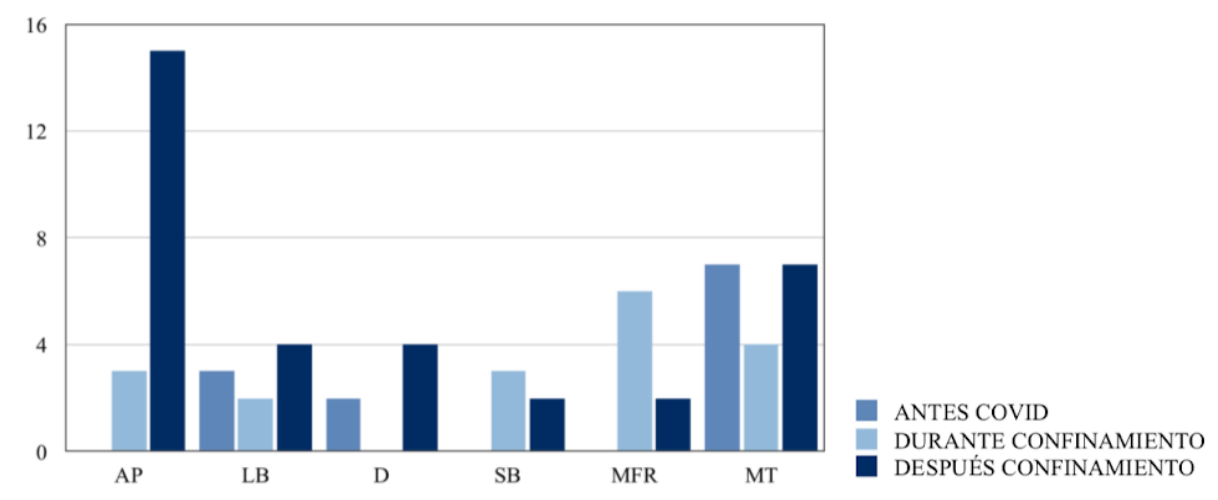

Fuente: Elaboración propia

Si bien la Ley de Autocontrol entraba en vigor el 1 de enero de 2021, fue a inicios de 2020 cuando se comenzó a plantear la cuestión de la señalización de todas aquellas publicaciones con contenido publicitario, es por ello que numerosas influencers optaron por comenzar a indicar cuando era una colaboración pagada, un regalo de la marca o una acción publicitaria a través del hashtag \#Ad o \#Supplied, en caso de ser un regalo de la marca, o etiquetado desde la propia aplicación Instagram como "Colaboración pagada" con la marca correspondiente.

Esto se ve claramente reflejado en la figura 15, pues casos como el de Alexandra Pereira, Sara Baceiredo o María Fernández-Rubíes, en los que no habían señalizado 
ninguna de los posts publicitarios entre enero y febrero de 2020, sí que comenzaron a hacerlo durante los meses de confinamiento. Destacable especialmente la actividad de Alexandra Pereira, que pasa de señalar tres publicaciones durante el periodo de estudio que abarca los meses de abril y mayo de 2020, a quince publicaciones señalizadas durante las semanas analizadas en enero y febrero de 2021.

En general, aumenta la cifra de publicaciones distinguidas como contenido publicitario. Sin embargo, casos como el de Sara o María Fernández-Rubíes desciende esta cifra en el tercer periodo estudiado en comparación con las semanas de confinamiento, algo curioso, pues, en el caso de María, aumentó exponencialmente la aparición de marcas en sus publicaciones en este mismo periodo.

Como se mencionaba anteriormente, además de aquellas publicaciones en las que sí se indica el contenido publicitario de las mismas, existen otras tantas publicaciones en las que es prácticamente imposible reconocer si se trata de una acción publicitaria, un regalo de la marca o una compra realizada por la misma influencer que ha decidido etiquetar a la marca. En este caso, se han categorizado como publicaciones sin determinar.

\section{Figura 9.}

Total publicaciones con marcas sin determinar.

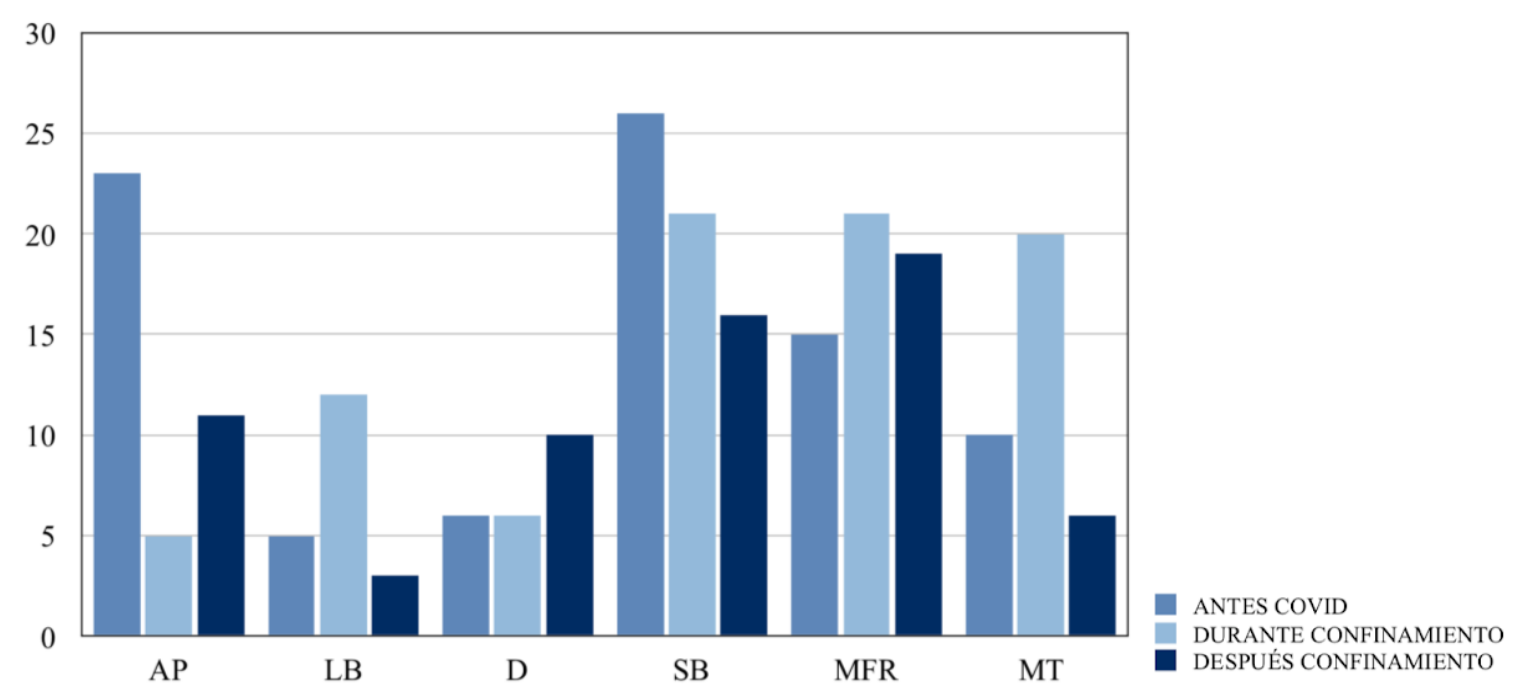

Fuente: Elaboración propia

En este tipo de publicación van también inmersas aquellas en las que las influencers muestran y etiquetan productos de sus propias marcas, como el caso de It's Lava, de Sara Baceiredo, o las diferentes colecciones cápsulas que lanzan con marcas ya en el mercado, como la colección de Dulceida para Sephora.

Como ya se ha comentado en el análisis de las publicaciones en las que aparecen marcas, Sara Baceiredo y Alexandra Pereira acostumbraban en los meses previos a la 
pandemia a etiquetar la gran mayoría de productos y establecimientos que aparecían en sus publicaciones, al contrario que lo que sucedía con Mery Turiel, Dulceida o Lucía Bárcena.

En el caso de Alexandra Pereira, la disminución de publicaciones sin marcas se ve claramente compensada por el aumento de posts con publicidad correctamente etiquetada y con el aumento, a su vez, de publicaciones de carácter personal en las que no incluye marcas. También destaca que, siendo el perfil más influyente, Dulceida sea de las influencer con menos marcas mencionadas sin especificar el origen de los productos, pues, cruzando los datos con la gráfica de la figura 15, en la que se analiza la cantidad de publicaciones en las que se señaliza de manera correcta la publicidad, se deja entrever que, sin necesidad de etiquetar todos los productos que utiliza, el estilo de moda y de vida de Dulceida sigue siendo influyente por sí mismo.

También cabe resaltar que existe una involucración por parte de la influencer con sus públicos en la que genera respuesta a los comentarios con dudas acerca de marcas y productos que aparecen en los distintos posts. Por otro lado, el aumento de publicaciones con marcas sin determinar si son o no publicidad que experimenta el perfil de Mery Turiel durante el periodo estudiado en abril y mayo de 2020, se debe, principalmente, a la iniciativa que puso en marcha para mostrar productos de diferentes marcas de moda española durante las semanas de confinamiento. Estas publicaciones contaban con productos de diversas firmas españolas, pero no mencionaba qué tipo de colaboración existía entre ellas.

En el análisis de este factor se encuentran también casos de emplazamiento publicitario, pues ya lo advertía Méndiz (2007) y así ha sido a lo largo de los años, "los anunciantes reducirán progresivamente sus presupuestos en la cuenta de publicidad tradicional. Y como consecuencia las agencias van a orientar su creatividad y sus estrategias comunicativas hacia otros campos."

De esta manera, especialmente en el periodo de enero y febrero de 2020, se realizaban publicaciones en las que se etiquetaban o mencionaban a marcas que aparecían en la publicación de manera "casual", sin concretar en la mayoría de las ocasiones que se trataba de una acción publicitaria. Pese a que el product placement sigue estando presente en el marketing con influencers, se han reducido considerablemente los casos en los que no se señaliza la publicidad con la marca, pues no puede olvidarse la entrada en vigor el 1 de enero de 2021 de la nueva Ley de Autocontrol en el marketing con influencers.

Además de lo mencionado anteriormente, durante este análisis se han detectado diferentes ocasiones en las que las colaboraciones de las influencers con ciertas marcas coincidían en el tipo de contenido, en la información adjunta y ofrecida en la publicación y en el periodo de tiempo en que la publicaban. 
Este hecho se debe a que numerosas marcas lanzan campañas publicitarias a través de diferentes influencers, lo que genera publicaciones bastante similares en los perfiles de distintas prescriptoras en un mismo periodo de tiempo. En los periodos de análisis de esta investigación cabe destacar los casos de campañas para:

\section{Tabla 3.}

Resumen campañas de marcas

\begin{tabular}{|c|c|c|c|c|}
\hline Marca & Influencers & Fecha & Imagen & Acción \\
\hline Isdin & $\begin{array}{l}\text { María Fdez. } \\
\text { Rubíes; Sara } \\
\text { Baceiredo }\end{array}$ & Mayo 2020 & $\begin{array}{l}\text { Look con el } \\
\text { producto, Imagen } \\
\text { detalle productos } \\
\text { y más accesorios } \\
\text { (D/MFR) }\end{array}$ & $\begin{array}{l}\text { Marca etiquetada, mención } \\
\text { marca en texto, hashtag \#ad, } \\
\text { \#GANASdesol (D/MFR) }\end{array}$ \\
\hline $\begin{array}{l}\text { Louis } \\
\text { Vuitton } \\
\text { (Louisette) }\end{array}$ & $\begin{array}{l}\text { Dulceida (D); } \\
\text { María Fdez. } \\
\text { Rubíes (MFR); } \\
\text { Lucía Bárcena }\end{array}$ & $\begin{array}{l}\text { Enero y } \\
\text { Febrero } 2021\end{array}$ & $\begin{array}{l}\text { Primer plano } \\
\text { portando } \\
\text { producto } \\
\text { (D/MFR), } \\
\text { Bodegón (LB) }\end{array}$ & $\begin{array}{l}\text { Marca etiquetada, mención } \\
\text { marca y producto en texto } \\
\text { (D/MFR/LB) \#ad (MFR), } \\
\text { \#SupliedbyLouisVuitton (LB) } \\
\text { \#supplied (D) }\end{array}$ \\
\hline $\begin{array}{l}\text { Bicis } \\
\text { Clásicas }\end{array}$ & $\begin{array}{l}\text { Sara Baceiredo } \\
\text { (SB); Mery } \\
\text { Turiel (MT) }\end{array}$ & Mayo 2020 & $\begin{array}{l}\text { Look con el } \\
\text { producto (SB/MT) }\end{array}$ & $\begin{array}{l}\text { Sorteo (SB/MT), marca } \\
\text { etiquetada }(\mathrm{MT}) \text {, mención en } \\
\text { pie de foto, seguimiento marca } \\
\text { para sorteo (SB/MT). }\end{array}$ \\
\hline Pull \& Bear & $\begin{array}{l}\text { Sara Baceiredo } \\
\text { (SB); Mery } \\
\text { Turiel (MT) }\end{array}$ & Febrero2020 & $\begin{array}{l}\text { Look con el } \\
\text { producto (SB/MT) }\end{array}$ & $\begin{array}{l}\text { Marca etiquetada, mención en } \\
\text { texto (SB/MT), \#ad } \\
\text { \#pullandbearcommunity (MT). }\end{array}$ \\
\hline $\begin{array}{l}\text { Perfect } \\
\text { Moment } \\
\text { Sport / } \\
\text { Baqueira }\end{array}$ & $\begin{array}{l}\text { Alexandra } \\
\text { Pereira (AP), } \\
\text { María Fdez } \\
\text { Rubíes (MFR), } \\
\text { Lucía Bárcena } \\
\text { (LB) }\end{array}$ & Enero 2020 & $\begin{array}{l}\text { Look con el } \\
\text { producto } \\
\text { (AP/MFR/LB) y } \\
\text { localización } \\
\text { (MFR/LB) }\end{array}$ & $\begin{array}{l}\text { Marca etiquetada, ubicación } \\
\text { (AP/MFR/LB); etiqueta lugar y } \\
\text { mención lugar } n \text { texto } \\
\text { (MFR/LB), \# espiritubaqueira } \\
\text { (MFR). }\end{array}$ \\
\hline $\begin{array}{l}\text { Esteé } \\
\text { Lauder }\end{array}$ & $\begin{array}{l}\text { Alexandra } \\
\text { Pereira (AP), } \\
\text { María Fdez } \\
\text { Rubíes (MFR) }\end{array}$ & Febrero 2021 & $\begin{array}{l}\text { Look con el } \\
\text { producto } \\
\text { (AP/MFR), } \\
\text { bodegón (MFR), } \\
\text { Primer plano } \\
\text { producto (AP) }\end{array}$ & $\begin{array}{l}\text { Marca etiquetada en imagen, } \\
\text { mención marca en texto, \# } \\
\text { advancednightrepair } \\
\text { \# esteepartner } \\
\text { \#GenerationANR \#AD } \\
\text { (AP/MFR) }\end{array}$ \\
\hline
\end{tabular}

Fuente: Elaboración propia

Además de las mencionadas anteriormente, existen otras colaboraciones de las influencers analizadas en esta investigación que coinciden en campañas publicitarias de las mismas marcas de moda y belleza. Sin embargo, no siempre coinciden en tiempo las publicaciones realizadas para esas marcas o el tipo de contenido que existe en ellas. 


\subsection{Resultados de las entrevistas en profundidad}

Tras conseguir la respuesta de las influencers a las preguntas que se planteaban anteriormente para conocer la relación que establecen las prescriptoras con las marcas de moda y belleza y cómo ha evolucionado esta relación a partir de la llegada de la pandemia, se puede concretar que, si bien la cantidad de contratos ha disminuido, al igual que se ha reducido el tiempo por el que se extienden las campañas y los acuerdos de colaboración en todos estos meses anteriores, actualmente comienza a producirse un ligero aumento en estos aspectos. Por otro lado, se confirma que la relación entre influencers y marcas es más sólida y cercana.

Las influencers sostienen que han visto afectado su trabajo con la llegada de la pandemia, pues las marcas de moda y belleza se vieron obligados a reducir gastos y presupuestos, por lo que, el trabajo de agencia se vio bastante afectado y el tipo de contenido cambió hacia uno más útil e influenciado por las nuevas tendencias de formato que ofertaron las redes, como los reels de Instagram o los vídeos de Tik Tok. Sin embargo, afirman que la pandemia, especialmente durante las semanas de confinamiento, les ha permitido a muchas de ellas poder crear mayor cantidad de contenido $y$, al aumentar la audiencia general en redes sociales, han experimentado un aumento de seguidores, por lo que se podría hacer un balance positivo de la situación.

Por otro lado, la relación que establecen con las marcas también ha experimentado algunos cambios: ya no surgen tan rápido ni de manera tan sencilla como en el periodo pre-pandemia, si no que suelen comenzar con giftings (regalos por parte de las marcas) que se convierten en acciones puntuales o campañas de poca duración debido a la situación de incertidumbre actual.

En este punto, llama la atención cómo existen dos versiones absolutamente contrarias entre las propias influencers, y es que algunas cuentan cómo han disminuido de manera drástica los contratos a largo plazo, y otras, por el contrario, narran bajo su experiencia cómo las marcas buscan una relación laboral más extensa que antes de la pandemia. En lo que todas coinciden es en que las marcas prefieren contenidos de carácter emocional, más inspirador y humano.

La relación entre ambos agentes se ha estrechado debido a las dificultades de la situación: tanto las influencer como las marcas reman en la misma dirección y esto les ha hecho unirse aún más según los testimonios de las insiders.

En cuanto a las estrategias y tendencias que han cambiado con la llegada de la pandemia, hablan de una menor celebración de eventos presenciales, reduciéndose la cifra casi en un $90 \%$ según los testimonios recogidos, y aquellos que de manera excepcional se celebran, tienen un aforo mucho más reducido que se limita a las influencers más cercanas a la marca y no suelen estar remunerados, algo que ocurre también con los viajes de marca. Igual sucede con las estrategias de campaña: las prescriptoras cuentan cómo han notado una preferencia por parte de las marcas por influencers con las que ya habían trabajado anteriormente y con las que mantienen una relación estable. 
Sin embargo, hay un hecho en el que todas están de acuerdo, y es en la nueva tendencia de eventos y presentaciones online, pues además de tener una gran acogida por parte de las influencers y sus públicos, resultan útiles, amenos, rápidos $y$, en general, necesitan de una inversión menor que los eventos presenciales.

\section{CONCLUSIONES}

Una vez se han expuesto y analizado los resultados obtenidos a partir de las técnicas de investigación se pueden hallar diversas conclusiones.

La llegada de la pandemia ha afectado laboralmente a las influencers de moda y belleza, pues durante el confinamiento experimentaron un aumento en sus audiencias, en el engagement generado y en trabajos con las marcas, pero también han experimentado una reducción en la cantidad de propuestas de trabajo por parte de las marcas y han surgido cambios en los requerimientos y duración de las campañas.

Actualmente, ambos agentes se enfrentan a situaciones de incertidumbre que provocan que las marcas reduzcan sus presupuestos e inversiones publicitarias, lo que las lleva a optar por acciones más concretas con una menor cantidad de perfiles, al elegir influencers con las que ya mantengan relación laboral estable.

Por el contrario, en las fechas posteriores a los meses de confinamiento, concretamente en enero y febrero de 2021, periodo que abarca el estudio de esta investigación, también disminuyen los datos que de manera general habían aumentado durante las semanas de cuarentena.

Todo ello confirma nuestro primer objetivo, que las influencers especializadas en moda y belleza han modificado su forma de trabajo debido a la pandemia.

En referencia al contenido publicado en los perfiles más influyentes del sector, se aprecia cómo existe aumento de publicaciones de carácter personal durante las semanas de confinamiento, pese a experimentar también crecimiento aquellas publicaciones en las que aparece contenido generado para las marcas. En general, aumenta la cantidad de publicaciones, y se experimenta con los nuevos formatos que ofrecen las plataformas.

Además, los contenidos se ven adaptados a un único escenario interior, en las semanas de cuarentena. Esta unión de datos hace que se confirme nuestro segundo objetivo: Las influencers de moda y belleza se han visto obligadas a modificar el tipo de contenido que comparten en sus perfiles de Instagram a causa de la pandemia.

En relación con las marcas de moda y belleza, las prescriptoras coinciden en un aumento de la calidad del contenido que requieren las campañas, pues exigen publicaciones más emocionales, orgánicas y útiles para el espectador, que conecte mejor con los públicos.

A pesar de esto, las relaciones entre influencers y marcas se encuentran más reforzadas, pues han desarrollado una relación empática de manera bidireccional que les permite remar en la misma dirección a pesar de los cambios. Teniendo todo ello 
en cuenta, pese a existir cambios en las condiciones de trabajo entre las influencers y las marcas, la relación se mantiene estable y en continuidad de manera generalizada, como así lo han confirmado los testimonios de las entrevistadas.

Por último, atendiendo a la nueva normativa de autocontrol y código de conducta de las influencers, se debe tener en cuenta su entrada en vigor el 1 de enero de 2021, por lo que se entiende que durante el confinamiento no estaban obligadas de manera legal a indicar aquellas apariciones de marcas que eran concretamente publicidad.

Pese a ello, y en general, salvo algunas excepciones, se ha producido un incremento en las publicaciones señalizadas como publicidad, durante las semanas de confinamiento $y$ en el periodo estudiado post-confinamiento, aunque el mayor crecimiento teniendo cuenta este factor, se ha dado en aquellas publicaciones en las que aparecen marcas etiquetadas o mencionadas pero no se determina si es contenido publicitario, por lo tanto, ni se confirma ni se refuta el cuarto objetivo propuesto las influencers no han cumplido con la nueva normativa de autocontrol y código de conducta durante los meses de confinamiento en pandemia.

\section{REFERENCIAS}

Alonso, T. (2020). Marketing de influencers: el antes y el después del coronavirus. FashionNetwork.com. https://bit.ly/3i3f1jp

Arenas, M. (2010) Redes Sociales, ¿Un virus sin cura?: Las ventajas y los problemas para sus usuarios. https://bit.ly/33BNykV

Cardoso-Pereira, P. A. (2018). Un viaje a través de Instagram: una investigación cualitativa sobre las estrategias utilizadas por los influencers españoles. [Trabajo Final de Máster. Universidad Autónoma de Barcelona].

Autocontrol (2020). Código de Conducta sobre el Uso de Influencers en la Publicidad. https://bit.ly/3fMUfDm

Baquedano, R. (2021). Entrevista en profundidad: del diseño al análisis (con ejemplos). FREED TOOLS. https://bit.ly/3zBTOhY

Barón, M., Duque, L., Mendoza, F., y Quintero, W. (2021). Redes sociales y relaciones digitales, una comunicación que supera el cara a cara. Revista Internacional de Pedagogía e Innovación Educativa, 1(1), 123-148. https://doi.org/10.51660/ripie.v1i1.29

Baron, C. (2015). La Pirámide del Influencer Engagement: los 3 tipos de influencia. https://bit.ly/3eYNP3O

Blasco-Hernández, T. y Otero García, L. (2008). Técnicas conversacionales para la recogida de datos en investigación cualitativa: La entrevista (I). NURE investigación: Revista Científica de enfermería, (33). 
Casaló, V., Flavián, C., e Ibáñez-Sánchez, S. (2018). The relevance of creativity and emotions in engaging users on Instagram. Global Marketing Conference, Tokyo.

Castells, M. (2009). Comunicación y poder. Alianza Editorial.

Chiorboli, D. (2020). Influencer marketing post covid-19: cómo ha evolucionado y cómo las marcas pueden adaptarse a los cambios. https://bit.ly/2VdJFhF

Coleman, S. (2012). Believing the news: From sinking trust to atrophied efficacy. European Journal of Communication, 1(27), 35-45. https://doi.org/10.1177/0267323112438806

Colle, R. (2011). El análisis de contenido de las comunicaciones. Cuadernos Artesanos. Sociedad Latina de Comunicación Social.

Comscore (2020). Consumo de medios durante la pandemia de coronavirus. https://bit.ly/32pUotg

Comunicare. (2021). Marketing y comunicación de moda. Comunicare. Agencia de Marketing Online. https://bit.ly/2USOfna

Costa, J. (2015). Creación y gestión de marcas. Revista Imagen y comunicación. https://bit.ly/3FOduaa

Cristófol-Rodríguez, C., Alcalá-Vidal, A., y Fernández-Pérez, L. (2018). Análisis comparativo de las aplicaciones Snapchat e Instagram: nuevas tendencias derivadas de su uso. Redmarka: revista académica de marketing aplicado, 20, 39-76. https://doi.org/10.17979/redma.2018.01.020.4801

de Castro, L. (2019). Análisis de la evolución y el uso de social media como estrategia de marketing digital. Marketing de influencers. [Trabajo Fin de Grado. Universidad de Sevilla]. https://bit.ly/3iOEM6G

Díaz, L. (2017). Soy marca: quiero trabajar con influencers, influencer marketing. Profit.

Figuereo-Benítez, J. C., González-Quiñones, F., y Machín-Mastromatteo, J. D. (2021). Instagram como objeto de estudio en investigaciones recientes. Una revisión de literatura con enfoque en revistas científicas. Ámbitos: Revista internacional de comunicación, 53, 9-23. https://dx.doi.org/10.12795/Ambitos.2021.i53.01

Guerrero-Hueso, E. (2017). Nuevas tendencias en el marketing de influencia: el caso de Instagram [Trabajo Fin de Grado, Universidad Politécnica de Cartagena]. Repositorio Digital de la Universidad Politécnica de Cartagena. https://repositorio.upct.es/handle/10317/6041

IAB (2021). Estudio de Redes Sociales 2021. https://bit.ly/3rAKbml

INFOADEX. (2021). Estudio Infoadex de la inversión publicitaria en España 2021. https://bit.ly/3ycOB50 
Katz, E. y Lazarsfeld, P. F. (1955). Personal Influence. The part played by people in the flow of mass communications. $A$ report of the Bureau of Applied Social Research. The Free Press. https://doi.org/10.4324/9781315126234

Khan, S. (2018). Instagram as a marketing tool for luxury brands. International Journal of Management, Business and Research, 8(2).

Krippendorff, K. (1990). Metodología de análisis de contenido. Teoría y Práctica. Paidós Comunicación.

Jódar-Marín, J. A. (2010). La era digital: nuevos medios, nuevos usuarios y nuevos profesionales. Razón y palabra, (71).

L2 Fashion Team. (2017). L2 Digital IQ Index: Fashion 2017. Gartner Research. https://gtnr.it/3FKSEZ6

Laato, S., Najmul, A., Nazrul, M., y Whelan, E. (2020). Why do people share misinformation during the Covid-19 pandemic? Cornell University. https://arxiv.org/abs/2004.09600

Lazarsfeld, P. F., Berelson, B. y Gaudet, H. (1944) The People'S Choice: How the Voter Makes Up His Mind in a Presidential Campaign. Columbia University Press. https://doi.org/10.7312/laza93930

León, N. (2020). Técnicas de investigación cuantitativa y cualitativa. We are testers. https://bit.ly/376naxQ

López, N. y Sandoval, I. (2016). Métodos y técnicas de investigación cuantitativa y cualitativa. [Documento de trabajo. Universidad de Guadalajara]. https://bit.ly/33IZAZE

Lozares-Colina, C. (2005) Bases socio-metodológicas para el Análisis de Redes Sociales. ARS EMPIRIA. Revista de Metodología de las Ciencias Sociales, 10, pp. 9-35.

Luque Ortiz, S. (2019). La imagen de marca de los influencers y su repercusión en el consumo a través de Instagram. En G. Paredes Otero (Ed.), Investigar las redes sociales. Un acercamiento interdisciplinar (pp. 217-244). Egregius

Méndiz-Noguero, A. (2007). Nuevas formas publicitarias. Patrocinio, product placement, publicidad en Internet. Spicum

Mention Solutions (2021). Instagram Engagement Report 2021. https://bit.ly/3AAThnj

Merodio, J. (2013). Qué es el marketing de influencia y cómo usarlo dentro de tu estrategia de contenidos. JUANMERODIO. https://bit.ly/3Am8Fng

Peréz, V., Aguirre-Cruz, C., y Guerrero-Velástegui, C. (2020). Influencers como Estrategia de Posicionamiento de las Pymes del Sector Textil. RECITIUTM, 
Revista Electrónica de Ciencia y Tecnología del Instituto Universitario de Tecnología de Maracaibo 6(2), 1-28.

Piñuel-Raigada, J. L. (2002). Epistemología, metodología y técnicas del análisis de contenido. Estudios de sociolingüística, 30(1), pp. 1-42.

Piza-Burgos, N. D., Amaiquema-Márquez, F. A. y Beltrán-Baquerizo, G. E. (2019). Métodos y técnicas en la investigación cualitativa. Algunas precisiones necesarias. Conrado, 15(70), 455-459.

Regadera-González, E. (2020). ¿Puede ser la crisis de la covid-19 una oportunidad para el sector de la moda? The Conversation. https://bit.ly/3lanaVs

Rose, J. (2017). Marketing en Instagram. Babelcube Inc.

Ruiz-Cartagena, J. J. (2017). Millennials y redes sociales: estrategias para una comunicación de marca efectiva. Miguel Hernández Communication Journal, (8), 347-367.

Salesupply. (2021) Informe 2020: El sector de la Moda Española Online. https://bit.ly/3y8kYlj

San-Cornelio, G. (2020). Investigar sobre comunicación en las redes en tiempos de confinamiento. COMeIN: Revista de los Estudios de Ciencias de la Información y de la Comunicación, (98). https://doi.org/10.7238/c.n98.2028

Silva-Robles, C. (2014). Instagram, generación de contenidos y marcas de lujo: la narración de historias como estrategias de comunicación. En D. Fernández Quijada y M. Ramos-Serrano (Eds.), Tecnologías de la persuasión: uso de las TIC en publicidad y relaciones públicas. (pp. 181-196). UOC.

Statista. (2021). Number of global social network users 2017-2025. https://bit.ly/3f2MjOD

Taylor, S. J. y Bogdan, R. (2008). La entrevista en profundidad. Métodos cuantitativos aplicados, 2, 194-216.

Ugalde, N. y Balbastre, F. (2013). Investigación cuantitativa e investigación cualitativa: buscando las ventajas de las diferentes metodologías de investigación. Revistas de Ciencias Económicas, 31(2), 179-187.

Velar-Lera, M., Herrera-Damas, S., y González-Aldea, P. (2020). Uso de Instagram para la comunicación de las marcas de moda de lujo. Palabra Clave, 23(4), 1-32. https://doi.org/10.5294/pacla.2020.23.4.4

Wolfe, A. W. (2011). Anthropologist view of social network analysis and data mining. Social Network Analysis and Mining. https://bit.ly/3i7opmL 


\section{Contribuciones de los autores:}

Conceptualización: Gutiérrez Ortega, Paloma, Cristófol-Rodríguez, C. Metodología: Gutiérrez Ortega, Paloma, Cristófol-Rodríguez, C. Validación: Gutiérrez Ortega, Paloma, Cristófol-Rodríguez, C. Análisis Formal: Guerrero Navarro, Daniel. Investigación: Gutiérrez Ortega, Paloma. Redacción preparación del borrador original: Gutiérrez Ortega, Paloma. RedacciónRevisión y Edición: Cristófol-Rodríguez, $C_{i}$, Guerrero Navarro, D. Visualización: Guerrero Navarro, D. Supervisión: Guerrero Navarro, D y Cristófol-Rodríguez, C. Todos los autores han leído y aceptado la versión publicada del manuscrito: Gutiérrez Ortega, Paloma, Cristófol-Rodríguez, C., Guerrero Navarro, D.

\section{AUTOR/ES:}

\section{Daniel Guerrero Navarro}

Doctor en Comunicación Audiovisual y Publicidad. Master en Gestión Comercial y Dirección de Marketing. Licenciado en Publicidad y Relaciones Públicas. Licenciado en Periodismo. Profesor Asociado de la Facultad de Ciencias de la Comunicación de la Universidad de Málaga desde hace 17 años. Director de Desarrollo de Negocio y Marketing de la empresa tecnológica BeSoccer.

Orcid ID: https://orcid.org/0000-0001-6563-3851

Google Scholar: https://scholar.google.es/citations?user=a8IAc3EAAAAJ\&hl=es

\section{Carmen Cristófol-Rodríguez (autor de referencia)}

Doctora en Comunicación y Licenciada en Publicidad y Relaciones Públicas (UMA). Participa como IP en Proyectos de Innovación Docente, como evaluadora en revistas de reconocido prestigio, y como miembro de tribunales de tesis y trabajos fin de máster. Editora de sección de Revista Mediterránea de Comunicación, investigadora en los grupos COMPUBES (Comunicación y Públicos Específicos) y IICCXXI (Industrias Culturales Hoy), ambos de la Universidad de Alicante. Es socia de la AEIC (sección 10) y AIRRPP. Forma parte del Programa de Doctorado Interuniversitario. Tiene experiencia docente en universidades públicas y privadas y en docencia virtual y presencial. Durante 17 años ha compaginado su labor docente e investigadora con su faceta como profesional de los medios de comunicación. Cuenta con un sexenio de investigación.

Orcid ID: https://orcid.org/0000-0001-9766-6500

Google Scholar: https://scholar.google.es/citations?user=FAOooOwAAAAJ\&hl=es

ResearchGate: https://publons.com/researcher/3485105/carmen-cristofol/

Scopus: https://www.scopus.com/authid/detail.uri?authorId=57220745891

\section{Paloma Gutiérrez Ortega}

Graduada en Publicidad y Relaciones Públicas por la Universidad de Málaga 